\title{
BMR
}

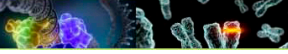

\section{Association between the XPG gene Asp1104His polymorphism and lung cancer risk}

\author{
B. Zhou, X.M. Hu and G.Y. Wu \\ Department of Thoracic Surgery, Hunan Provincial Tumor Hospital, \\ Changsha, China \\ Corresponding author: B. Zhou \\ E-mail: zhoubin1300@126.com
}

Genet. Mol. Res. 15 (2): gmr.15027395

Received August 7, 2015

Accepted May 11, 2016

Published June 10, 2016

DOI http://dx.doi.org/10.4238/gmr.15027395

\begin{abstract}
It has been suggested that the xeroderma pigmentosum complementation group $\mathrm{G}(X P G)$ gene Asp1104His polymorphism is linked to susceptibility to lung cancer. However, the results from the published studies are contradictory rather than conclusive. With this meta-analysis, we aimed to achieve a better understanding of the effects of the $X P G$ gene Asp1104His polymorphism on lung cancer risk. We identified six eligible studies from five publications that included a total of 2293 lung cancer patients and 2586 controls. There was a significant association between the $X P G$ gene Asp1104His polymorphism and lung cancer (His/His $v s$ Asp/Asp: OR $=1.24,95 \% \mathrm{CI}=1.04-1.48$; Asp/His vs Asp/Asp: $\mathrm{OR}=1.17,95 \% \mathrm{CI}=1.03-1.34$; the dominant model: $\mathrm{OR}$ $=1.18,95 \% \mathrm{CI}=1.04-1.33$; the recessive model: $\mathrm{OR}=1.10,95 \% \mathrm{CI}=$ 0.94-1.28). In a subgroup analysis by nationality, we found a significant association between the $X P G$ gene Asp1104His polymorphism and lung cancer risk in Asians. No publication bias was found in this study. The results from this meta-analysis indicate that the $X P G$ gene Asp1104His polymorphism is associated with lung cancer risk, especially in Asians.
\end{abstract}

Key words: Lung cancer; $X P G$ gene; Genetic variant; Meta-analysis 


\section{INTRODUCTION}

Lung cancer is the leading cause of cancer-related mortality worldwide, and was responsible for approximately 87,750 deaths in men and 72,590 in women in 2012 in the United States (Siegel et al., 2012). The mechanism of lung carcinogenesis is still not fully understood. Well-known environmental risk factors for lung cancer include arsenic, asbestos, radon, and polycyclic aromatic hydrocarbons, especially those present in cigarette smoke (Youlden et al., 2008). However, not all people who have been exposed to those risk factors develop lung cancer, which suggests that cancer susceptibility varies between individuals (Neumann et al., 2005). Increasing evidence for the association between genetic factors and lung cancer risk has been identified in recent years, suggesting that genetic factors may play an important role in the pathogenesis of lung cancer (Brennan et al., 2011).

Without properly functioning DNA repair mechanisms, cells may suffer various types of DNA damage. The nucleotide excision repair (NER) system plays a key role in DNA repair. The xeroderma pigmentosum complementation group $\mathrm{G}(X P G)$ gene, also referred to as the excision repair cross-complementation group 5 (ERCC5) gene, is an important component of the NER system. The $X P G$ gene has the chromosomal locus 13q22-q33, and consists of 15 exons and 14 introns (Emmert et al., 2001). The Asp1104His polymorphism (National Center for Biotechnology Information (NCBI) ID: rs17655) results in an aspartic acid-to-histidine transition at position 1104 in exon 15, which may affect protein activity in the NER system and alter genetic susceptibility to cancer (Collins and Harrington, 2002). Previous metaanalyses have indicated that the $X P G$ gene Asp1104His polymorphism may be a risk factor for gastrointestinal cancers and head and neck cancer (Luo et al., 2014; Jiang et al., 2015).

To date, several molecular epidemiologic case-control studies have shown the potential role of the $X P G$ gene Asp1104His polymorphism in the risk of lung cancer. However, the results remain inconclusive and controversial. A single study may not have sufficient power to detect a possible small effect of the polymorphisms on lung cancer, especially when the sample size is relatively small. Hence, we performed a meta-analysis of all eligible studies to derive a more precise estimation of the associations between $X P G$ gene Asp1104His polymorphism and lung cancer.

\section{MATERIAL AND METHODS}

\section{Publication search}

We searched the electronic literature databases PubMed and Web of Science for all relevant articles. The last search update was June 2015, and we used the search terms: ('nucleotide excision repair', 'NER', and 'lung cancer') and ('Asp1104His' and 'rs17655') and ('polymorphism', 'SNP', 'allele', and 'variant'). All the references included in the review and original articles on this topic were also checked. When the same patient population was included in different articles, the article with the largest number of participants, or the most recent article was selected.

\section{Inclusion and exclusion criteria, and data extraction}

The studies included in the meta-analysis were required to meet all the following 
criteria: 1) there was an evaluation of the association between the XPG gene Asp1104His polymorphism and the risk of lung cancer; 2) the study was case-control; 3) the study had been reported as a full-text article; and 4) there was sufficient data for estimating odds ratios (ORs) with $95 \%$ confidence intervals (95\%CIs). Exclusion criteria were: studies without genotype or allele data; case reports; studies containing overlapping data; non-human studies; and editorials or review articles (including meta-analyses).

Information was carefully extracted from all eligible publications by two independent investigators according to the inclusion criteria listed above. For conflicting evaluations, an agreement was reached following discussion. The information extracted from each study included the first author, year of publication, ethnicity of the population studied, number of subjects in each category, and the counts of people with different genotypes in cases and controls. Information on the Hardy-Weinberg equilibrium test (HWE) was also tracked or calculated if unavailable.

\section{Statistical analysis}

The strength of the association between the $X P G$ gene Asp1104His polymorphism and lung cancer risk was assessed using the pooled ORs with $95 \%$ CIs. The pooled estimations were made using several genetic models, including homozygote comparison (His/His vs Asp/ Asp), heterozygote comparison (Asp/His vs Asp/Asp), dominant model (Asp/His+His/His vs Asp/Asp), and recessive model (His/His vs Asp/His+Asp/Asp). Between-study heterogeneity was quantified using the $\mathrm{I}^{2}$ value. The $\mathrm{I}^{2}$ value describes the percentage of variation across studies caused by heterogeneity rather than chance, where $\mathrm{I}^{2}=0 \%$ indicates no observed heterogeneity; $25 \%$ is regarded as low; $50 \%$ as moderate; and $75 \%$ as high (Higgins et al., 2003). When heterogeneity was found among the included studies, the pooled OR was estimated using the fixed-effects model $\left(\mathrm{I}^{2}<50 \%\right)$. Otherwise, the random-effects model was used. The HWE was checked in controls using the chi-square test, and a P value less than 0.05 represented significant deviation from the HWE (Rohlfs and Weir, 2008). The sensitivity analysis was performed by omitting one study at a time to determine the magnitude of influence on the overall summary estimate (Zintzaras et al., 2005). Publication bias was investigated by funnel plot and Begg's funnel (a P value less than 0.05 was representative of statistical significance). The statistical analyses were performed using STATA 12.0 software (StataCorp, College Station, TX, USA).

\section{RESULTS}

\section{Eligible studies}

The search strategy retrieved 266 potentially relevant studies. Based on the inclusion criteria, six case-control studies from five publications were included (Jeon et al., 2003; Shen et al., 2005; Sakiyama et al., 2005; Cui et al., 2006; Chang et al., 2008). The flow chart for the study selection is summarized in Figure 1. The six case-control studies included a total of 2293 patients and 2586 healthy controls. The publication years of the studies ranged from 2003 to 2010. All the articles were written in English; three studies were on Asians and three studies were on other races. The genotype distributions in the controls in all the studies were 
in accordance with the HWE except for in the Jeon et al. study. The main characteristics of the included studies are summarized in Table 1.

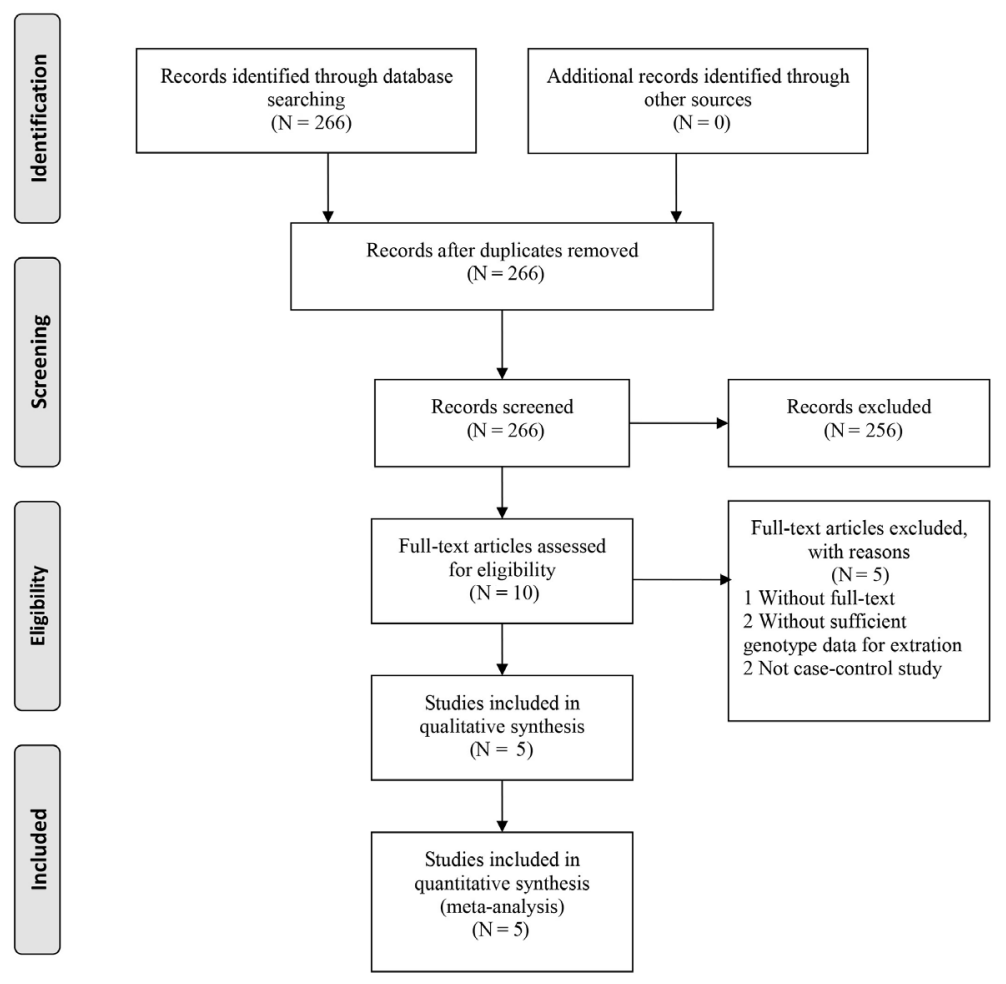

Figure 1. Flow chart of study selection.

Table 1. Characteristics of the studies included in the meta-analysis.

\begin{tabular}{l|l|l|c|c|c|c}
\hline \multirow{2}{*}{ First author (year) } & Country & Ethnicity & Cases/controls & \multicolumn{3}{|c}{ XPG Asp1104His (case/control) } \\
\cline { 4 - 7 } & & & & His/His & Asp/His & Asp/Asp \\
\hline Jeon et al. (2003) & Korea & Asian & $310 / 311$ & $88 / 89$ & $164 / 132$ & $58 / 90$ \\
\hline Shen et al. (2005) & China & Asian & $116 / 109$ & $38 / 38$ & $52 / 46$ & $26 / 25$ \\
\hline Sakiyama et al. (2005) & Japan & Asian & $1002 / 685$ & $202 / 124$ & $500 / 333$ & $300 / 228$ \\
\hline Cui et al. (2006) & USA & Mixed & $497 / 902$ & $41 / 78$ & $212 / 356$ & $244 / 468$ \\
\hline Chang et al. (2008a) & USA & Hispanic & $113 / 299$ & $9 / 34$ & $44 / 127$ & $60 / 138$ \\
\hline Chang et al. (2008b) & USA & African & $255 / 280$ & $68 / 49$ & $119 / 138$ & $68 / 93$ \\
\hline
\end{tabular}

\section{Meta-analysis}

A summary of the meta-analysis findings of the association between the $X P G$ gene Asp1104His polymorphism and lung cancer risk is shown in Figure 2 and Table 2. The combined results based on all studies showed that the $X P G$ gene Asp1104His polymorphism is associated with increased lung cancer risk (His/His $v s \mathrm{Asp} / \mathrm{Asp}: \mathrm{OR}=1.24,95 \% \mathrm{CI}=1.04-$ 1.48; Asp/His vs Asp/Asp: OR = 1.17, 95\%CI = 1.03-1.34; the dominant model: $\mathrm{OR}=1.18$, $95 \% \mathrm{CI}=1.04-1.33$; the recessive model: $\mathrm{OR}=1.10,95 \% \mathrm{CI}=0.94-1.28)$. In the subgroup 
analysis based on ethnicity, a significant association was found between the AGTR1 gene A1166C polymorphism and breast cancer risk in Asians (His/His vs Asp/Asp: OR $=1.28$, $95 \% \mathrm{CI}=1.02-1.60 ;$ Asp/His vs Asp/Asp: $\mathrm{OR}=1.35,95 \% \mathrm{CI}=0.93-1.96$; the dominant model: $\mathrm{OR}=1.31,95 \% \mathrm{CI}=0.97-1.77$; the recessive model: $\mathrm{OR}=1.07,95 \% \mathrm{CI}=0.88-1.29$ ).

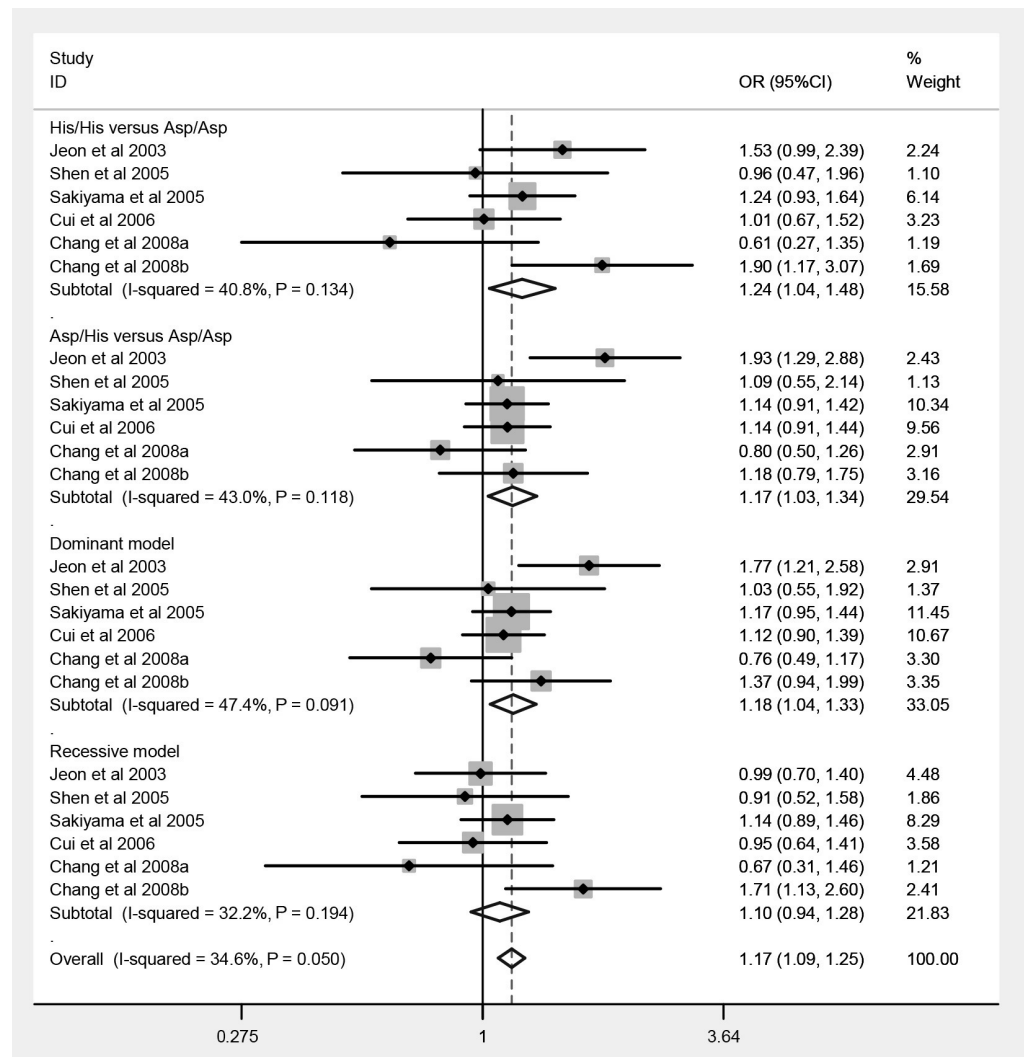

Figure 2. Forest plot of lung cancer associated with the XPG gene Asp1104His polymorphism.

Table 2. Summary of the different comparative results.
\begin{tabular}{l|c|c|c|c|c}
\hline Variables & $\mathrm{N}$ & $\begin{array}{c}\text { His/His versus Asp/Asp } \\
\text { OR }(95 \% \mathrm{CI}) ; \mathrm{P} \text { value; } \mathrm{I}^{2}\end{array}$ & $\begin{array}{c}\text { Asp/His versus Asp/Asp } \\
\text { OR }(95 \% \mathrm{CI}) ; \mathrm{P} \text { value; } \mathrm{I}^{2}\end{array}$ & $\begin{array}{c}\text { Dominant model } \\
\text { OR }(95 \% \mathrm{CI}) ; \mathrm{P} \text { value; } \mathrm{I}^{2}\end{array}$ & $\begin{array}{c}\text { Recessive model } \\
\text { OR }(95 \% \mathrm{CI}) ; \mathrm{P} \text { value; } \mathrm{I}^{2}\end{array}$ \\
\hline Total & 6 & $1.24(1.04-1.48) ; 0.13 ; 40.8 \%$ & $1.17(1.03-1.34) ; 0.12 ; 43.0 \%$ & $1.18(1.04-1.33) ; 0.09 ; 47.4 \%$ & $1.10(0.94-1.28) ; 0.19 ; 32.2 \%$ \\
\hline Ethnicity & & & & & \\
\hline Asian & 3 & $1.28(1.02-1.60) ; 0.52 ; 0.0 \%$ & $1.35(0.93-1.96) ; 0.07 ; 61.9 \%$ & $1.31(0.97-1.77) ; 013 ; 50.5 \%$ & $1.07(0.88-1.29) ; 0.67 ; 0.0 \%$ \\
\hline Others & 3 & $1.11(0.62-1.99) ; 0.03 ; 71.3 \%$ & $1.09(0.92-1.30) ; 0.35 ; 5.2 \%$ & $1.06(0.82-1.42) ; 0.12 ; 52.2 \%$ & $1.10(0.66-1.82) ; 0.04 ; 68.3 \%$ \\
\hline
\end{tabular}

$\mathrm{N}=$ number; $\mathrm{OR}=$ odds ratio; $\mathrm{CI}=$ confidence interval; $\mathrm{I}^{2}=$ inconsistency index.

Sensitivity analysis was performed to assess the influence of each individual study on the pooled OR by deleting one study at a time. When omitting each data set in the metaanalysis, the pooled ORs were always persistent (Figure 3). No single study influenced the pooled ORs qualitatively, as indicated by sensitivity analyses, suggesting that the results of this meta-analysis were stable. 


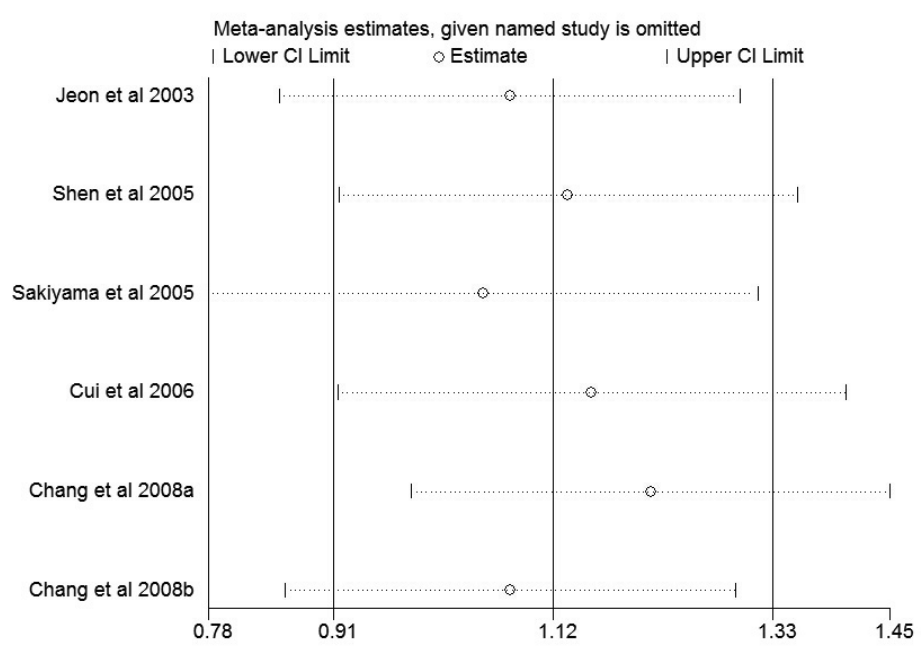

Figure 3. Results of sensitivity analysis from fixed-effects estimates.

\section{Publication bias}

Funnel plots and Begg's tests were used to assess the publication bias in the literature. There was no evidence of publication bias in our study. The results implied that the publication bias was low in the present meta-analysis (Figure 4).

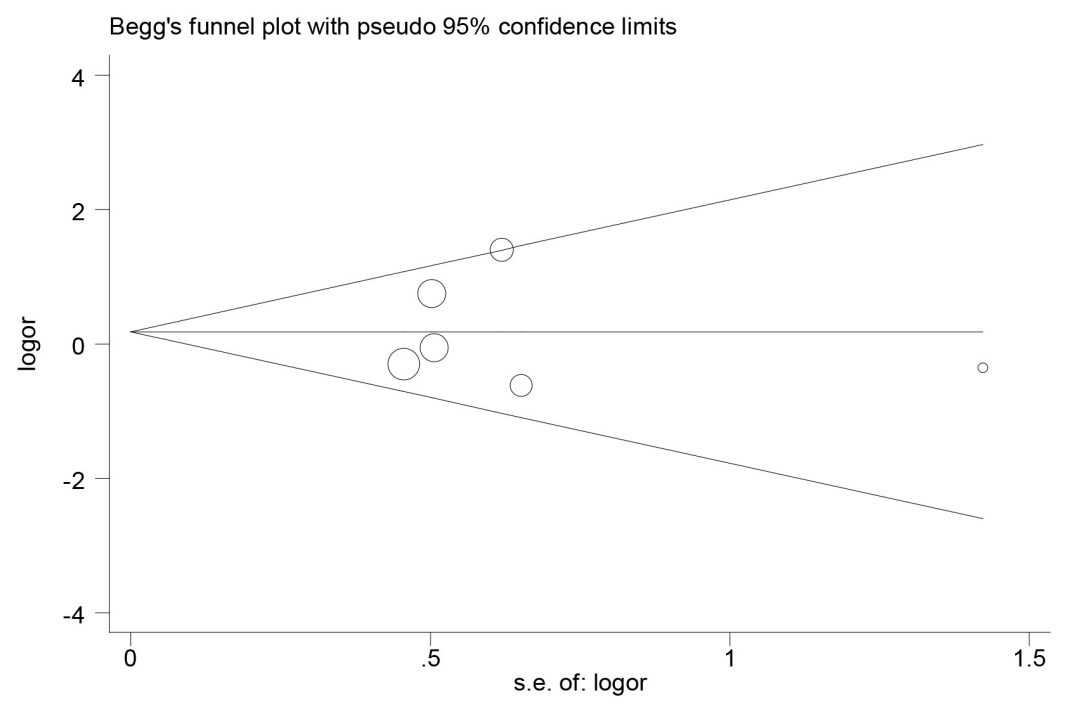

Figure 4. Begg's funnel plot for the publication bias test. 


\section{DISCUSSION}

Lung cancer is the leading cause of cancer-related mortality worldwide. Despite the high morbidity and mortality of lung cancer, its etiology remains unknown. Multiple factors contribute to lung cancer, among which genetic factors play an important role. DNA repair mechanisms play a key role in the protection of cells from DNA damage and in the maintenance of genomic integrity. Recently, some studies have reported that the XPG gene Asp1104His polymorphism is associated with the risk of lung cancer. However, the results remained inconsistent. Individual studies may have been insufficiently powered to detect the effect of polymorphisms on susceptibility to lung cancer (Fallin et al., 2001). To shed light on the association between the $X P G$ gene Asp1104His polymorphism and lung cancer risk, we conducted a meta-analysis of several recent case-control studies.

This meta-analysis included six case-control studies, involving 2293 patients with lung cancer and 2586 healthy controls. When all the studies were pooled together, our results suggested that the $X P G$ gene Asp1104His polymorphism is associated with lung cancer risk. Subgroup analyses were performed according to ethnicity, and the results revealed that the $X P G$ gene Asp1104His polymorphism has a statistically significant association with increased lung cancer risk in Asians. This might be accounted for by ethnic differences and diverse environment. In addition, the ethnic differences may be due to chance because studies with small sample size may have insufficient statistical power to detect small effects (Wacholder et al., 2004). Further sensitivity analysis confirmed a significant association between the $X P G$ gene Asp1104His polymorphism and lung cancer risk. There was no evidence of publication bias in this meta-analysis of the XPG gene Asp1104His polymorphism.

Some limitations of this meta-analysis should be acknowledged. First, we were unable to obtain more original data, and the results were based on unadjusted estimates, lacking the evaluation of the covariates of age, smoking and alcohol consumption, and other environmental factors. This may have affected the evaluation of the interaction between genes and the environmental, or other factors. Second, the number of studies and the number of subjects in the studies included in the meta-analysis by specific subgroups were small. Finally, we only included articles written in English, so we may have missed some articles.

This meta-analysis provided evidence of an association between the XPG gene Asp1104His polymorphism and risk of lung cancer. Further studies that estimate the effect of gene-gene and gene-environment interactions may eventually provide a better, comprehensive understanding of the association.

\section{Conflicts of interest}

The authors declare no conflict of interest.

\section{REFERENCES}

Brennan P, Hainaut P and Boffetta P (2011). Genetics of lung-cancer susceptibility. Lancet Oncol. 12: 399-408. http:// dx.doi.org/10.1016/S1470-2045(10)70126-1

Chang JS, Wrensch MR, Hansen HM, Sison JD, et al. (2008). Nucleotide excision repair genes and risk of lung cancer among San Francisco Bay Area Latinos and African Americans. Int. J. Cancer 123: 2095-2104. http://dx.doi. org/10.1002/ijc. 23801 
Collins A and Harrington V (2002). Repair of oxidative DNA damage: assessing its contribution to cancer prevention. Mutagenesis 17: 489-493. http://dx.doi.org/10.1093/mutage/17.6.489

Cui Y, Morgenstern H, Greenland S, Tashkin DP, et al. (2006). Polymorphism of Xeroderma Pigmentosum group G and the risk of lung cancer and squamous cell carcinomas of the oropharynx, larynx and esophagus. Int. J. Cancer 118: 714-720. http://dx.doi.org/10.1002/ijc.21413

Emmert S, Schneider TD, Khan SG and Kraemer KH (2001). The human XPG gene: gene architecture, alternative splicing and single nucleotide polymorphisms. Nucleic Acids Res. 29: 1443-1452. http://dx.doi.org/10.1093/nar/29.7.1443

Fallin D, Cohen A, Essioux L, Chumakov I, et al. (2001). Genetic analysis of case/control data using estimated haplotype frequencies: application to APOE locus variation and Alzheimer's disease. Genome Res. 11: 143-151. http://dx.doi. org $/ 10.1101 /$ gr. 148401

Higgins JP, Thompson SG, Deeks JJ and Altman DG (2003). Measuring inconsistency in meta-analyses. BMJ 327: $557-$ 560. http://dx.doi.org/10.1136/bmj.327.7414.557

Jeon HS, Kim KM, Park SH, Lee SY, et al. (2003). Relationship between XPG codon 1104 polymorphism and risk of primary lung cancer. Carcinogenesis 24: 1677-1681. http://dx.doi.org/10.1093/carcin/bgg120

Jiang HY, Zeng Y, Xu WD, Liu C, et al. (2015). Genetic Association between the XPG Asp1104His Polymorphism and Head and Neck Cancer Susceptibility: Evidence Based on a Meta-Analysis. Asian Pac. J. Cancer Prev. 16: 36453651. http://dx.doi.org/10.7314/APJCP.2015.16.9.3645

Luo JF, Yan RC and Zou L (2014). XPG Asp1104His polymorphism and gastrointestinal cancers risk: a meta-analysis. Int. J. Clin. Exp. Med. 7: 4174-4182. PubMed

Neumann AS, Sturgis EM and Wei Q (2005). Nucleotide excision repair as a marker for susceptibility to tobacco-related cancers: a review of molecular epidemiological studies. Mol. Carcinog. 42: 65-92. http://dx.doi.org/10.1002/ mc.20069

Rohlfs RV and Weir BS (2008). Distributions of Hardy-Weinberg equilibrium test statistics. Genetics 180: 1609-1616. http://dx.doi.org/10.1534/genetics.108.088005

Sakiyama T, Kohno T, Mimaki S, Ohta T, et al. (2005). Association of amino acid substitution polymorphisms in DNA repair genes TP53, POLI, REV1 and LIG4 with lung cancer risk. Int. J. Cancer 114: 730-737. http://dx.doi. org/10.1002/ijc.20790

Shen M, Berndt SI, Rothman N, Demarini DM, et al. (2005). Polymorphisms in the DNA nucleotide excision repair genes and lung cancer risk in Xuan Wei, China. Int. J. Cancer 116: 768-773. http://dx.doi.org/10.1002/ijc.21117

Siegel R, Naishadham D and Jemal A (2012). Cancer statistics, 2012. CA Cancer J. Clin. 62: 10-29. http://dx.doi. org/10.3322/caac. 20138

Wacholder S, Chanock S, Garcia-Closas M, El Ghormli L, et al. (2004). Assessing the probability that a positive report is false: an approach for molecular epidemiology studies. J. Natl. Cancer Inst. 96: 434-442. http://dx.doi.org/10.1093/ inci/djh075

Youlden DR, Cramb SM and Baade PD (2008). The International Epidemiology of Lung Cancer: geographical distribution and secular trends. J. Thorac. Oncol. 3: 819-831. http://dx.doi.org/10.1097/JTO.0b013e31818020eb

Zintzaras E, Chatzoulis DZ, Karabatsas CH and Stefanidis I (2005). The relationship between C677T methylenetetrahydrofolate reductase gene polymorphism and retinopathy in type 2 diabetes: a meta-analysis. J. Hum. Genet. 50: 267-275. http://dx.doi.org/10.1007/s10038-005-0250-z 